\title{
Pumpless, selective docking of yeast cells inside a microfluidic channel induced by receding meniscus $\uparrow$
}

\author{
Min Cheol Park, ${ }^{a}$ Jae Young Hur, ${ }^{b}$ Keon Woo Kwon, ${ }^{a}$ Sang-Hyun Park ${ }^{b}$ and Kahp Y. Suh*a \\ Received 27th February 2006, Accepted 31st May 2006 \\ First published as an Advance Article on the web 19th June 2006 \\ DOI: 10.1039/b602961b
}

We present a simple cell docking method induced by receding meniscus to capture non-adherent yeast cells onto microwells inside a microfluidic channel. Microwells were fabricated either by capillary moulding of UV curable polyurethane acrylate (PUA) onto glass substrate or direct replica moulding of poly(dimethyl siloxane) (PDMS). A cell suspension of the budding yeast, Saccharomyces cerevisiae, was introduced into the microfluidic channel by surface tension driven capillary flow and a receding meniscus was subsequently generated by evaporation. As the meniscus progressed, one to multiple yeast cells were spontaneously captured onto microwells by lateral capillary force created at the bottom of the meniscus. Using this cell-based platform, we observed the response of yeast cells upon stimulation by a mating pheromone ( $\alpha$-factor) by monitoring the expression of green fluorescent protein (GFP) with time. It was observed that $\alpha$-factor triggered the expression of GFP at $60 \mathrm{~min}$ after stimulation and the fluorescence intensity was sustained for an additional $60 \mathrm{~min}$ without changes.

\section{Introduction}

The budding yeast Saccharomyces cerevisiae is now recognized as a model system representing simple eukaryotic organisms whose genome can be easily traced and manipulated. Some of the properties that make yeast particularly suitable for biological studies include rapid growth, high dispersion, easy genetic manipulation and mutant isolation. S. cerevisiae was the first eukaryotic organism whose genome was completely sequenced. ${ }^{1}$ Subsequently, yeast became one of the key organisms for biological research, including extensive use of DNA microarrays, ${ }^{2,3}$ analysis of gene functions by gene disruption, ${ }^{4}$ serial analysis of gene expression (SAGE), ${ }^{5}$ enzymatic activities, ${ }^{6}$ and protein-protein interactions. ${ }^{7-9}$

In many cases, the yeast-based assays involve the use of green fluorescent protein (GFP) as a reporter. However, most current biological assays are based on large cell populations, which neglect single cell level information in the process of averaging fluorescence signals from GFP expression. For example, commonly used methods for high-throughput, cell-based assays are adapted to 96- and 384-well plate (recently 1536-well plates) formats. ${ }^{10-12}$ Despite the success of these assays, one fundamental limitation of plate-based assays is that the measured response is an average from heterogeneous populations of cells (i.e., ensemble averaging problem). Although the average cell response provides

${ }^{a}$ School of Mechanical and Aerospace Engineering and Institute of Advanced Machinery and Design, Seoul National University, Seoul 151-742, Korea

${ }^{b}$ School of Biological Sciences and Research Center for Functional Cellulomics, Seoul National University, Seoul 151-742, Korea.

E-mail: Kahp Y.Suh,sky4u@snu.ac.kr

$\dagger$ Electronic supplementary information (ESI) available: Video clips of surface tension driven capillary filling; 1 : receding meniscus induced docking (30 microwells); 2: receding meniscus induced docking (10 microwells). See DOI: 10.1039/b602961b valuable information about overall biological effects, it provides only partial information about the real cellular effects, since the response of each cell would vary depending on its physiological and genetic state. Therefore, it would be of benefit for biological research to develop a simple method that allows for large-scale cell-based assays at single cell level in a cheap, easy and high throughput manner.

One approach to overcoming some of the limitations is to introduce microfluidics or "lab-on-a-chip" (LOC) technology. ${ }^{13,14}$ These microfluidic devices offer the ability to work with smaller reagent volumes, shorter reaction times, and the possibility of high-throughput analysis. It is noted that spatial control or selective location of cells within microchannels is a prerequisite to enable high-throughput screening based on microfluidic devices. Recently, laminar flow patterning, ${ }^{15}$ pre-patterning with adhesive ligands, ${ }^{16,17}$ and immobilization inside hydrogels ${ }^{18}$ have been used to immobilize anchorage-dependent cells within microchannels. An alternative approach to patterning cells is based on cell-capturing or cell-trapping including hydrodynamic confinement, ${ }^{19}$ negative dielectrophoresis, ${ }^{20}$ optical tweezers, ${ }^{21}$ and microwells etched at the tip of a fiber-optic bundle. ${ }^{22}$ These methods, however, would have some limitations for easy, cheap, high-throughput microscopic studies of single cells. More recently, a simple soft lithographic method was introduced utilizing passive confinement of cells onto microwells aided by stationary conditions. $^{23,24}$ This is an attractive strategy due to its simplicity and low-expertise requirements. Conformal deposition of single or multiple cells, however, would be difficult to achieve using this approach since the cell-docking heavily relies on flow and surface conditions.

Here, we report a highly improved version of the soft lithographic approach using surface tension driven cell seeding and subsequent cell docking induced by a receding meniscus. Using this method, single to multiple cells can be accurately 
deposited onto microwells depending on the size of the microwell. Furthermore, a very small amount of volume $(<5 \mu \mathrm{L})$ is required for cell docking and subsequent cell assays, thus significantly enhancing the flexibility or portability of microfluidic devices. Although non-adherent yeast cells are tested here, our method could be applied to other anchoragedependent cells with slight modification of the experimental protocol.

\section{Methods and materials}

\section{Yeast strains, plasmids and materials}

The $S$. cerevisiae strains used in this study were SO992 (MATa, his3, leu2, ura3, trp1, pbs2) and SG3 (MATa, his3, leu2, ura3, trp1, met15, sis1-GFP). For monitoring $\alpha$-factor-dependent GFP expression SO992 cells were transformed with a pRS314based CEN/ARS plasmid carrying a mutant GFP (S65T) gene under control of the promoter from a mating response gene, Fus1, i.e. $\mathrm{P}_{\text {fus1-GFP (S65T). A peptide corresponding to }}$ $\alpha$-factor was chemically synthesized using F-moc chemistry and was purified by HPLC.

\section{PDMS mould fabrication for surface patterning and microfluidics}

PDMS and microfluidic moulds were fabricated by curing PDMS pre-polymer (Sylgard 184 Silicon elastomer, Dow Corning) on silicon masters prepared by photolithography. The masters used for surface patterning had receding (negative) square patterns $(10 \mu \mathrm{m}$ squares of $1 \mu \mathrm{m}$ height or $12 \mu \mathrm{m}$ squares of $12 \mu \mathrm{m}$ height), or $30 \mu \mathrm{m}$ protruding (positive) cylindrical features of $60 \mu \mathrm{m}$ height, resulting in PDMS replicas with the opposite sense. The masters used for microfluidic moulds had protruding (positive) features with the impression of microfluidic channels (in the range 200-800 $\mu \mathrm{m}$ in width and $\sim 80 \mu \mathrm{m}$ in height). To cure the PDMS prepolymer, a mixture of $10: 1$ silicon elastomer and the curing agent was poured on the master and placed at $70{ }^{\circ} \mathrm{C}$ for $1 \mathrm{~h}$. The PDMS replicas were then peeled from the silicon masters and cut prior to use. For the PDMS microfluidic moulds, holes were punched through the inlets and the outlets as reservoirs. Each reservoir had a hole of 3-4 $\mathrm{mm}$ in diameter, which allows for easy injection of the cell suspension and sufficient area for evaporating the residual cell suspension around the reservoir.

\section{Fabrication of the patterned microfluidic channels}

To fabricate the microstructures onto a glass substrate we used capillary moulding or replica moulding (Scheme 1). ${ }^{25,26}$ PUA microstructures were made of the UV curable polyurethane acrylate solution consisting of polyurethane pre-polymer with acrylate group, a photoinitiator, and a radiation-curable releasing agent as reported previously. ${ }^{27} \mathrm{~A}$ few drops of the PUA polymer solution were evenly distributed onto the glass substrate. A positive PDMS stamp with square patterns was then immediately placed in conformal contact with the polymer film and exposed to UV $(\lambda=250-400 \mathrm{~nm})$ for a few tens of seconds to cure (capillary moulding). For $30 \mu \mathrm{m}$ well microstructures, a negative PDMS stamp with $30 \mu \mathrm{m}$ cylindrical patterns was used for the patterned substrate
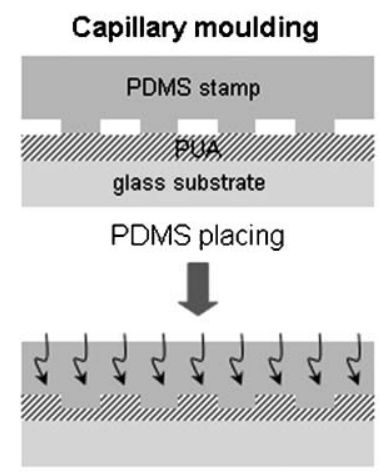

UV curing

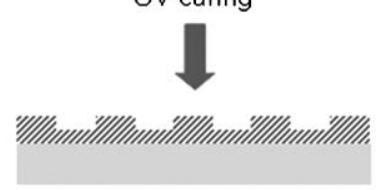

Plasma treating

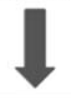

PDMS microfluidic mould

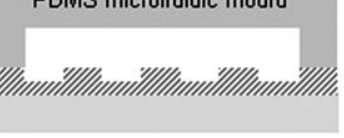

Positioning the microfluidic mould on top of the patterned substrate

Scheme 1 A schematic diagram of the fabrication of microchannel with patterned microstructures. Left column: A PUA microstructure with 10 or $12 \mu \mathrm{m}$ square wells was fabricated onto glass substrate by capillary moulding. Right column: A PDMS replica with $30 \mu \mathrm{m}$ cylindrical wells was obtained from the silicon master and used as the patterned substrate. The devices were completely sealed by plasma cleaning the patterned substrate and the PDMS microfluidic mould.

without replication (replica moulding). Once the microstructures were fabricated, the device was completed by plasma cleaning the patterned substrate (without disturbing the PDMS stamp) and the microfluidic mould at the same time for 45 s (60 W, PDC-32G, Harrick Scientific, Ossining, NY). After plasma treatment, the PDMS stamp was peeled from the substrate and the microfluidic mould was carefully aligned on the substrate, brought in conformal contact with the substrate and firmly pressed to form an irreversible seal. In some experiments the device was further sealed by heating on a hot plate for several hours.

\section{Scanning electron microscopy}

High-resolution scanning electron microscopy (SEM) images of the PUA microstructures were obtained using a HITACHI S-48000 microscope (Hitachi, Japan) operating at an accelerating voltage of $5 \mathrm{kV}$. To avoid charging effects, substrates were sputter-coated with $\mathrm{Au}$ to the thickness of $20 \mathrm{~nm}$ prior to measurements.

\section{Cell docking onto microwells inside a microfluidic channel}

The $S$. cerevisiae SG3 cells were grown at $30{ }^{\circ} \mathrm{C}$ in YPD medium to an $A_{600}$ of $\sim 0.5$ and the SO992 cells transformed with the plasmid $\mathrm{P}_{\text {fus } 1}-\mathrm{GFP}(\mathrm{S} 65 \mathrm{~T})$ were grown at $30{ }^{\circ} \mathrm{C}$ in a 
selective medium containing $2 \%$ dextrose to an $A_{600}$ of $\sim 0.5$ $\left(1.5 \times 10^{7}\right.$ cells $\left.\mathrm{mL}^{-1}\right)$. To capture the GFP-modified yeast cells onto microwells, a small amount of the solution was flowed into the microfluidic channel by surface tension driven capillary flow. The seeding amount was in slight excess of the volume of the channel to minimize the generation time of a meniscus such that the solution completely filled the channel and partially wetted the periphery of the outlet reservoir. For example, when a microfluidic channel was of $800 \mu \mathrm{m}$ in width, $80 \mu \mathrm{m}$ in height and $20 \mathrm{~mm}$ in length (maximum volume tested), the seeding amount was $2-5 \mu \mathrm{L}$, in excess of the channel volume $(1.28 \mu \mathrm{L})$.

To facilitate the directed evaporation, the opening of inlet reservoir was covered using a tape and then the medium in the outlet reservoir was left undisturbed to evaporate by natural convection at room temperature. After 5-10 min, a receding meniscus was generated and progressed towards the inlet reservoir. As the receding meniscus passed over the microwells, one to multiple yeast cells were spontaneously captured by lateral capillary force on the bottom of the meniscus. The remaining cells were accumulated in the inlet reservoir and were removed by a soft tissue paper if necessary. A schematic illustration of the cell docking procedure is shown in Scheme 2.

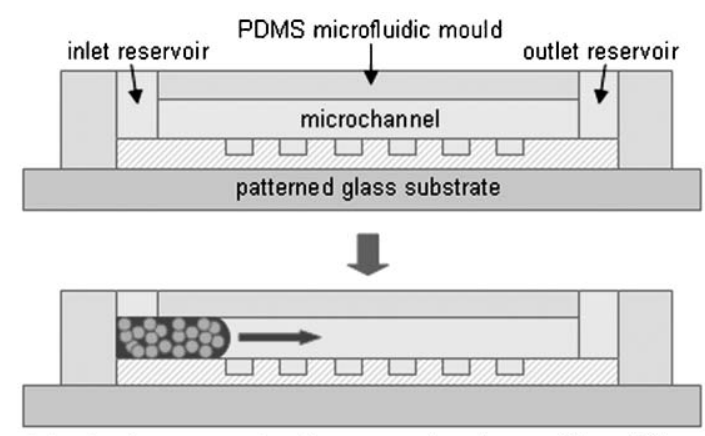

Introducing a yeast cell suspension by capillary filling

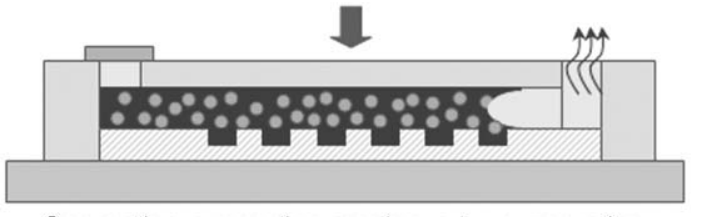

Generating a receding meniscus by evaporation

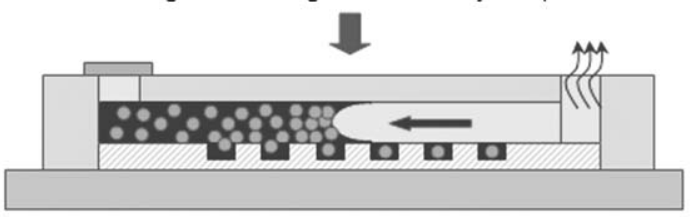

Capturing the cells by lateral capillary force

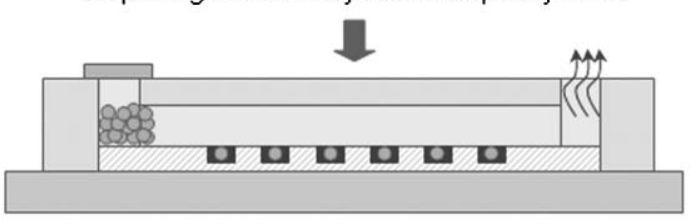

Receding meniscus induced docking

Scheme 2 A schematic diagram of the receding meniscus induced cell-docking method. A yeast cell suspension was flowed into the microchannel by surface tension-driven capillary filling and subsequently a receding meniscus was generated at the evaporating front.

\section{Analysis of cellular response to $\alpha$-factor}

To assess the cellular response to $\alpha$-factor, GFP expression was examined over time using an inverted fluorescence microscope (OLYMPUS IX71, Japan). Two flowing and detection schemes were used depending on the depth of the microwell. In the first scheme $(10 \mu \mathrm{m}$ square wells of $1 \mu \mathrm{m}$ height, shallow microwell), the cell suspension was stimulated with $\alpha$-factor to the final concentration of $10 \mu \mathrm{M}$ prior to flowing the cells into a microfluidic channel. Then, the stimulated yeast cells were introduced into the microfluidic channel and captured onto the microwells as illustrated in Scheme 2. After cell docking, the fluorescent images of the cells expressing GFP were taken every $30 \mathrm{~min}$ as the medium dried.

In the second scheme $(12 \mu \mathrm{m}$ square wells of $12 \mu \mathrm{m}$ height, deep microwell), the cell suspension was introduced into the channel without stimulation with $\alpha$-factor and subsequently the cells were captured by the same method. After cell docking, the remaining cells were washed by capillary flow of water from the inlet several times and removed at the outlet using a soft tissue paper. This step was repeated to completely evacuate the channel except for the medium and cells captured within microwells. Then, $\alpha$-factor was flowed into the channel from the inlet via capillary filling. The fluorescent images of the cells expressing GFP were taken every $30 \mathrm{~min}$ while covering the inlet and outlet to prevent evaporation of the $\alpha$-factor solution.

\section{Results and discussion}

\section{Fabrication of PUA microstructures onto glass substrate}

To pattern mammalian cells, previous research has primarily focused on poly(ethylene glycol) (PEG)-based polymer to modify surfaces. ${ }^{28-32}$ While a PEG-modified surface is very effective in patterning anchorage dependent cells, the use of PEG is not a requirement for non-adherent cell types such as yeast or blood cells. Moreover, direct, physical immobilization of a PEG template is sometimes not robust such that the layer is easily delaminated upon hydration due to swelling of the cross-linked PEG matrixes. To prevent delamination, 3-(trichlorosilyl)propyl methacrylate (TPM) was used as an adhesion promoting monolayer. ${ }^{29}$

To alleviate this potential problem, UV-curable PUA microstructures were fabricated and used as cell-docking microwells as shown in Scheme 1. In the course of capillary moulding, the PUA solution under the contact region is squeezed outside the protruding features of the PDMS stamp and moves into the void spaces by means of capillary action. $^{25,26}$ The PUA microstructures were subsequently cured by exposure to UV for a few tens of seconds and the PDMS mould was removed, rendering robust PUA structures with high physical integrity. Representative SEM images of the PUA microstructure are shown in Fig. 1. The pattern dimension here was (a) $10 \times 10 \mu \mathrm{m}$ or (b) $12 \times 12 \mu \mathrm{m}$ square wells, yielding a feature density of 2500 or 1736 wells $\mathrm{mm}^{-2}$, respectively. Higher-magnification $(\times 5000)$ SEM images in the inset show the well-defined PUA structure with good edge definition. The depth of each PUA microstructure was measured to be $\sim 1 \mu \mathrm{m}$ and $\sim 12 \mu \mathrm{m}$, respectively, 

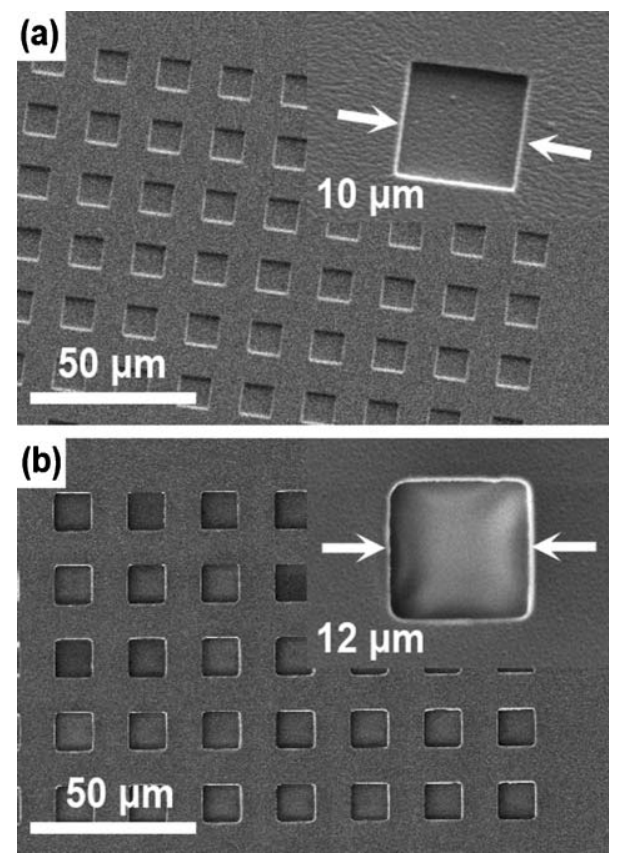

Fig. 1 SEM image of the PUA microstructures for (a) $10 \times 10 \mu \mathrm{m}$ square wells with $1 \mu \mathrm{m}$ height and (b) $12 \times 12 \mu \mathrm{m}$ square wells with $12 \mu \mathrm{m}$ height. The inset images show an enlarged view.

corresponding to the original height of the silicon master (not shown).

\section{Surface tension-driven capillary flow and subsequent generation of a receding meniscus}

In most microfluidic devices, an external pressure is applied to handle target samples where additional accessories such as a syringe pump, PE tubes and waste reservoirs are required. In the method presented here, the cell solution is spontaneously flowed inside a channel by surface tension driven capillary flow without the need for other accessories for pumping. As a result, the overall procedure is very simple and cheap, enabling an easy fabrication of a disposable biochip.

The rate of liquid flow in microcapillaries can be approximated using a simple kinetic equation that is given by ${ }^{33}$

$$
\frac{\mathrm{d} z}{\mathrm{~d} t}=\frac{R_{\mathrm{H}} \gamma_{\mathrm{LV}} \cos \theta}{4 \eta z}=\frac{R_{\mathrm{H}}\left(\gamma_{\mathrm{SV}}-\gamma_{\mathrm{SL}}\right)}{4 \eta z}
$$

where $R_{\mathrm{H}}$ is the hydraulic radius (the ratio of volume to surface area of the capillary), $\eta$ is the viscosity of the liquid, and $z$ is the length of the capillary movement, $\gamma_{\mathrm{SV}}, \gamma_{\mathrm{SL}}$ and $\gamma_{\mathrm{LV}}$ represent interfacial tensions at the solid/vapor, solid/liquid and liquid/vapor interfaces, respectively. In our experiments, the capillary filling was completed in a few seconds, in qualitative agreement with the theory presented above. Since the entire surfaces (the channel plus the substrate) were plasma cleaned, the wettability of aqueous solution was greatly enhanced, resulting in fast capillary flow inside the channel.

To facilitate the generation of a receding meniscus, a small amount of the cell solution $(<5 \mu \mathrm{L})$ was flowed into the channel such that the channel were completely filled while the outlet reservoir was partially wetted along the boundary.
Upon drying, a receding meniscus was spontaneously generated and then progressed towards the inlet reservoir at a speed increasing with increasing channel width. For example, the speed was measured at $7-8 \mu \mathrm{m} \mathrm{s}^{-1}$ at room temperature for a channel whose geometry was of $400 \mu \mathrm{m}$ width, $80 \mu \mathrm{m}$ height and $10 \mathrm{~mm}$ length, indicating that the evaporation rate was $0.224-0.256 \mathrm{~nL} \mathrm{~s}^{-1}$. In this case, it might take $20-30 \mathrm{~min}$ to evaporate the entire medium in the channel based on the channel dimension.

\section{Receding meniscus induced docking of yeast cells onto microwells}

As the meniscus receded, cells were spontaneously captured onto the microwells where the number of cells was determined depending on the size of the microwell. Fig. 2 shows brightfield and fluorescent images of the captured SG3 yeast cells (autofluorescent) for $30 \mu \mathrm{m}((\mathrm{a}),(\mathrm{c}),(\mathrm{e}))$ and $10 \mu \mathrm{m}$ wells ((b), (d), (f)), respectively. As shown in Fig. 2(a) and (b), the cell docking can be described by a sweeping process of the receding meniscus just like sweeping with a broom (see ESI video clips $1 \& 2 \dagger)$. Some cells were already captured by sedimentation prior to generation of a receding meniscus for $30 \mu \mathrm{m}$ wells, while the sedimentation was rarely found for $10 \mu \mathrm{m}$ wells. Fig. 2(c)-(f) represent brightfield and corresponding fluorescent images of the captured cells at a higher magnification. As shown in the figures, aggregated, stacked cells were seen for $30 \mu \mathrm{m}$ wells ((c) and (e)) (2-3 $\times$ $10^{2}$ cells well ${ }^{-1}$ ) whereas one to five cells were captured per each $10 \mu \mathrm{m}$ well ((d) and (f)). As the cell size ranges from $\sim 2$ to $\sim 8 \mu \mathrm{m}$, the maximum number of captured cells would
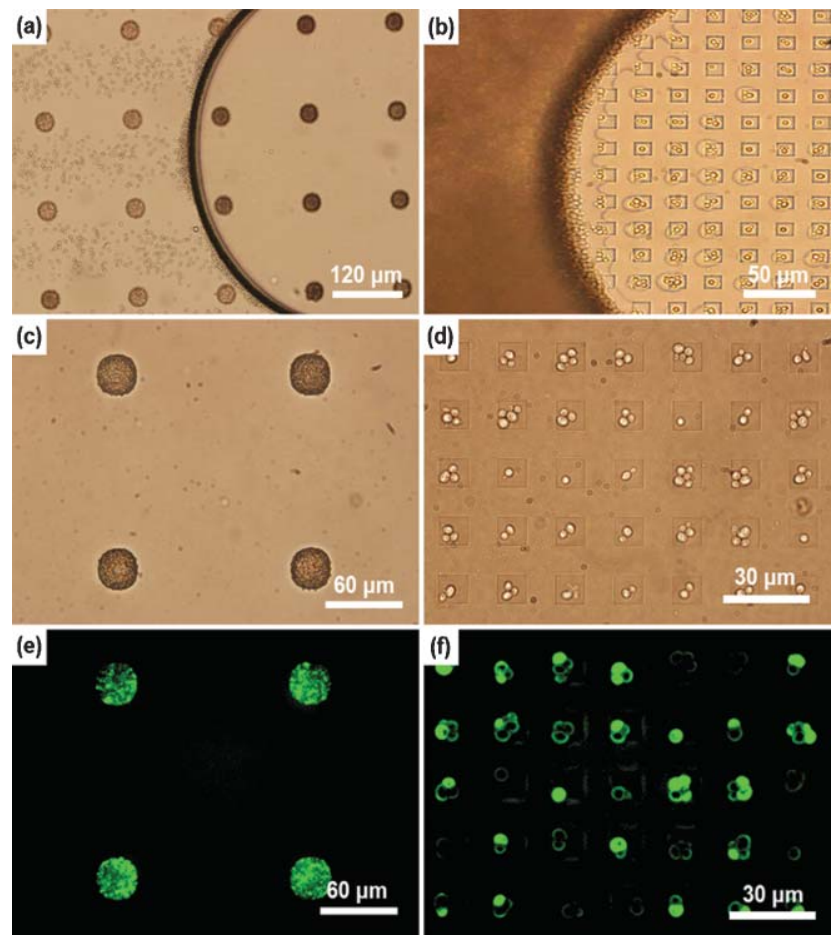

Fig. 2 Brightfield and fluorescent images of the captured SG3 yeast cells (autofluorescent) for $30 \mu \mathrm{m}$ ((a), (c), (e)) and $10 \mu \mathrm{m}$ wells ((b), (d), (f)), respectively. 
(a)

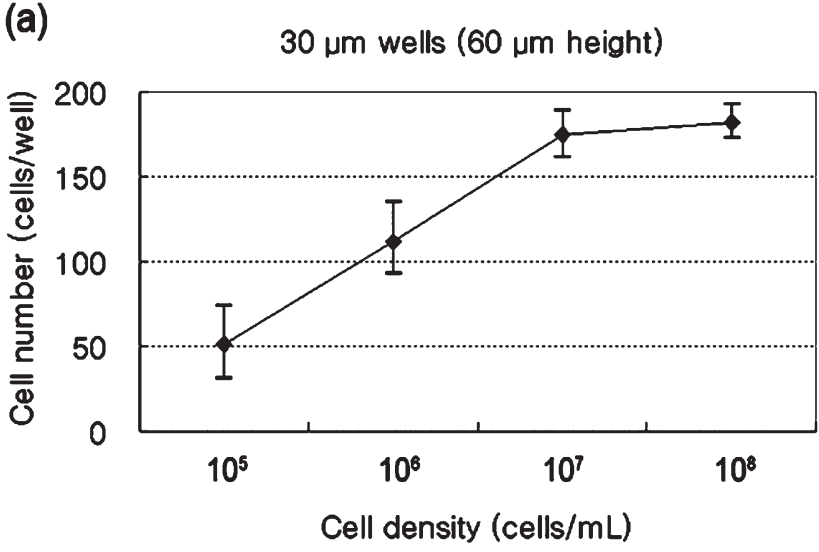

(b)

$10 \mu \mathrm{m}$ wells ( $1 \mu \mathrm{m}$ height)

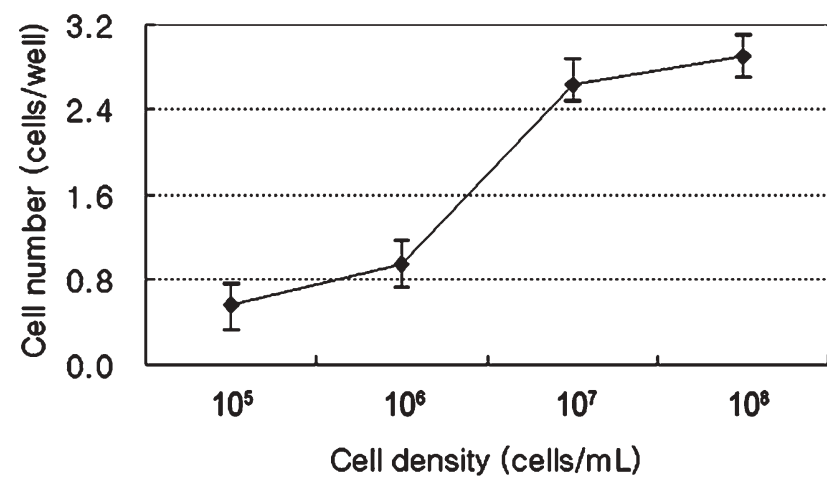

Fig. 3 The number of captured cells as a function of cell concentration for (a) $30 \mu \mathrm{m}$ wells with $60 \mu \mathrm{m}$ height, (b) $10 \mu \mathrm{m}$ wells with $1 \mu \mathrm{m}$ height. The error bars indicate variations from center to edge.

be five, in good agreement with the experiment. The fact that one to five cells can be captured simultaneously in a single screen of the viewer suggests that each cellular response can be tracked and compared with different populations. A notable feature is found in Fig. 2(f) that each cellular response, which is represented by the fluorescent intensity and distribution, was different from cell to cell. In comparison to an ensemble averaged signal shown in Fig. 2(e), this fact demonstrates the importance of extracting biological information at single cell level.

It is worthwhile noting that the cell density was a key parameter in determining the uniform cell docking. In particular, conformal deposition of single cells was destroyed when the initial cell density was reduced by several times. Apparently, the density used in this experiment $(\sim 1.5 \times$ $10^{7}$ cells $\mathrm{mL}^{-1}$ ) was a minimum for ensuring uniform cell docking. Fig. 3 shows the number of captured cells as a function of cell concentration for two microwells. For $30 \mu \mathrm{m}$ microwells of $60 \mu \mathrm{m}$ height, (a), the number of captured cells gradually increased with increasing concentration. The variations from center to edge, which are marked with error bars in the figure, increased with decreasing cell density, but conformal deposition was generally secured for all the concentrations tested. For $10 \mu \mathrm{m}$ microwells of $1 \mu \mathrm{m}$ height, (b), on the other hand, the number of captured cells rapidly decreased with decreasing cell density, with an apparent critical density of $\sim 1.5 \times 10^{7}$ cells $\mathrm{mL}^{-1}$. Below this concentration, the average cell density was less than unity, indicating that conformal deposition is nearly impossible to achieve.

A careful examination of the receding meniscus reveals that there is a thin layer at the bottom of the meniscus. In this region, the cells were separated from the meniscus at some point and subsequently located in the middle of the microwell. Previous work has shown that a lateral capillary force is generated between floating objects and drives self-assembly of the objects into the recessed region in a similar manner. ${ }^{34,35}$ As shown in snapshot images shown in Fig. 4 (time interval $\sim 30 \mathrm{~s}$ ), the presence of the thin film at the evaporating edge allows for partial wetting of the solution into the microwell (a), and at some point separation from the progressing meniscus (b). Then, the lateral capillary force drives the captured cell to be located in the middle (c). The direction of the net force applied on the cell is towards the center of the microwell because the lateral capillary force acts to flatten the deformed liquid layer. Some cells were not captured as shown in (d) presumably due to aggregation of cells. In this experiment, the cell density was very low (diluted by 1/100) for easy tracking of a target cell. Interestingly, the receding meniscus reached a steady state very rapidly such that the cell docking was essentially seen from the beginning of the meniscus.

\section{Analysis of cellular response to $\alpha$-factor}

To test for the potential use as a cell-based platform, we assessed the cellular response to $\alpha$-factor by monitoring a timelapse expression of GFP. This experiment was performed using a yeast cell suspension stimulated with $10 \mu \mathrm{M} \alpha$-factor. The $\alpha$-factor treated yeast cell suspension was flowed into a microfluidic channel by capillary filling. After the cells were captured, they were analyzed with time under an inverted
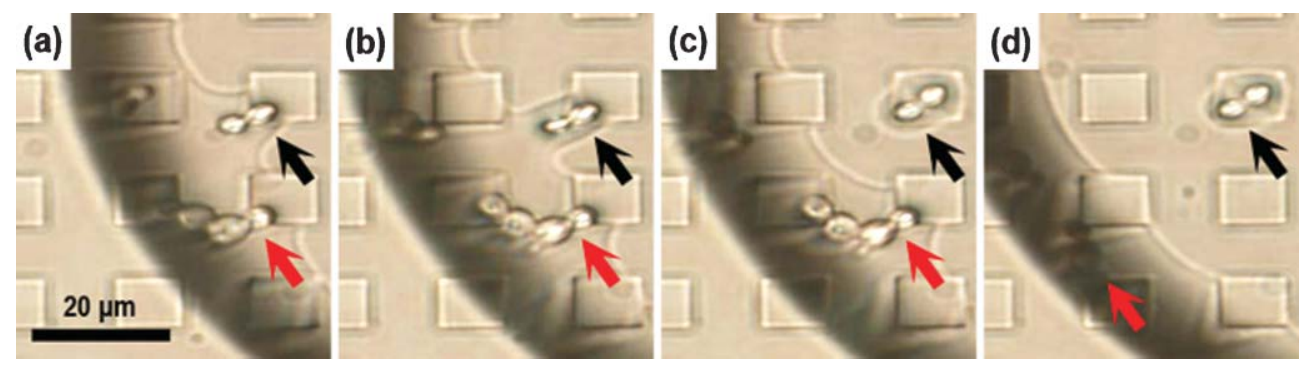

Fig. 4 An example of snapshot images of cell docking onto $10 \mu \mathrm{m}$ wells (time interval $\sim 30 \mathrm{~s}$ ). Individual cells were docked within a well (black arrows) but aggregated cells passes by the well without docking (red arrows). 

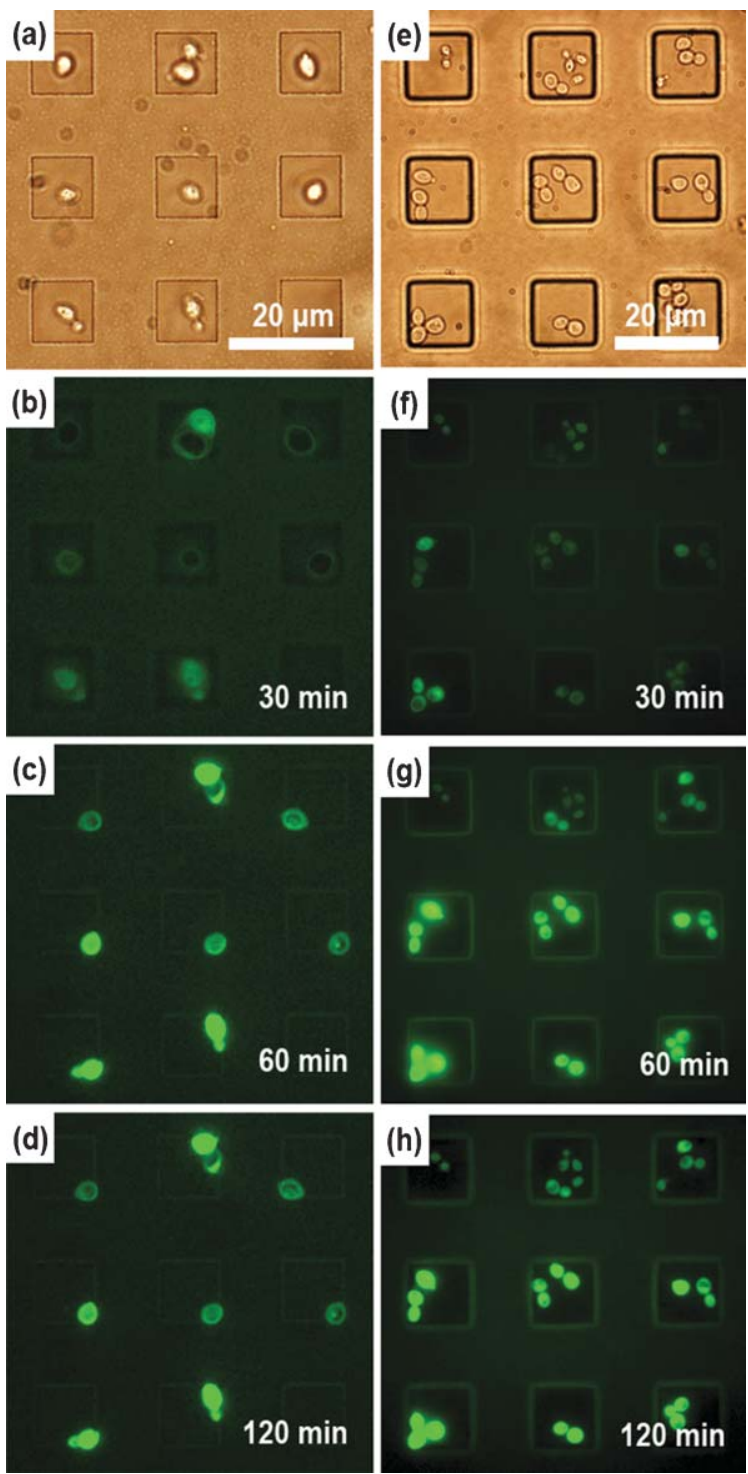

Fig. 5 Cellular response to $\alpha$-factor using two flowing and detection schemes for shallow ((a)-(d)) and deep wells ((e)-(h)). Brightfield ((a), (e)) and the corresponding time-lapse fluorescent images (b)-(d), (f)-(h)) are shown.

optical microscope. Fig. 5(a)-(d) shows brightfield (a) and corresponding time-lapse fluorescent images ((b)-(d)) of $\alpha$-factor-triggered GFP expression. In the initial state (30 min), GFP expression was not triggered as shown in (b). After $60 \mathrm{~min}$, GFP expression was triggered (c) and then the fluorescent intensity was maintained for an additional $60 \mathrm{~min}$ without appreciable changes (d). Also one can see that cells were initially located in the middle of the microwell (a) but slightly moved to the edge as the surrounding medium dried ((c), (d)). This detection scheme could be useful to study the influence of the ion concentration or osmolarity of the buffer solution over time.

One potential limitation with the above scheme is that the cells were pretreated with $\alpha$-factor prior to cell docking to prevent flooding of the as-deposited cells upon exposure to a laminar flow of biological reagents. It was observed that many docked cells readily escaped from $10 \mu \mathrm{m}$ wells even with a mild stream of solution $\left(\sim 3 \mu \mathrm{L} \min ^{-1}\right)$ since the height of microwells was merely $\sim 1 \mu \mathrm{m}$. On the contrary, essentially no flooding was observed in the case of $30 \mu \mathrm{m}$ wells $(\sim 60 \mu \mathrm{m}$ height) when the flow rate is less than $1 \mathrm{~mL} \mathrm{~min}^{-1}$. This was the reason why the cell suspension was pre-treated with $\alpha$-factor to assess the time-course cellular response instead of delivering the stimulating agent to the docked cells.

To address this flooding problem, an alternative flowing and detection scheme was devised such that $\alpha$-factor was delivered to the captured cells by pumpless, surface tension-driven capillary flow and diffusion (see Experimental section). The brightfield and corresponding time-lapse fluorescent images of the captured cells onto $12 \mu \mathrm{m}$ microwells of $12 \mu \mathrm{m}$ height are shown in Fig. 5(e)-(h). As similar to Fig. 5(a)-(d), GFP expression was triggered after $60 \mathrm{~min}(\mathrm{~g})$, and the intensity of GFP expression was maintained for additional $60 \mathrm{~min}(\mathrm{~h})$. In this experiment, the microfluidic channel was entirely filled with the $\alpha$-factor to leave the cells intact from exposure to air. It is envisioned that this latter scheme would be suitable for a long-term cell culture and detection or studying mammalian cells with slight modification of the protocol.

\section{Conclusions}

We have presented a simple, yet robust method to capture non-adherent yeast cells inside a microfluidic channel using a receding meniscus induced cell docking method. Well-defined PUA and PDMS microwells were fabricated within a microchannel by capillary and replica moulding, respectively. It was observed that one to multiple cells were spontaneously captured onto microwells depending on the well size as a receding meniscus swept the cells towards the inlet reservoir. The cell docking was highly reproducible with minimum variations from well to well. To enable conformal deposition of cells, the cell density was maintained above a certain value, in particular, for single-cell arrays. In addition, we have tested for the response of single cells to $\alpha$-factor by examining the expression of GFP over time. Two flowing and detection schemes were used depending on the depth of microwell.

There are some potential challenges and weaknesses with the current approach to be amenable for mammalian cells. First, a lot of cells are used to obtain single cell arrays, leaving behind a lot of waste at the inlet reservoir. This waste might be reusable by using a pumping system after the meniscusinduced cell docking. Second, the air/liquid interface, especially when the thickness of the liquid layer is thin, is difficult to control and thus is prone to non-uniformity. This challenge might be compromised with the use of a deeper microwell or a higher cell concentration. It is hoped that this simple approach would provide a valuable tool for highthroughput screening of single cell responses for non-adherent cells and further for anchorage-dependent cells with slight modification of the protocol.

\section{Acknowledgements}

The SG3 strain was a kind gift from Dr Won-Ki Huh at Seoul National University. This work was supported by the Micro 
Thermal System Research Center of Seoul National University and the Ministry of Science and Technology through Bio Tool R\&D Project for Cell Research. This work was also supported in part by the SRC program of MOST/KOSEF (R11-2005-009-02004-0) to S.-H. P.

\section{References}

1 A. Goffeau, B. G. Barrell, H. Bussey, R. W. Davis, B. Dujon, H. Feldmann, F. Galibert, J. D. Hoheisel, C. Jacq, M. Johnston, E. J. Louis, H. W. Mewes, Y. Murakami, P. Philippsen, H. Tettelin and S. G. Oliver, Science, 1996, 274, 546-567.

2 J. L. DeRisi, V. R. Iyer and P. O. Brown, Science, 1997, 278, 680-686.

3 P. O. Brown and D. Botstein, Nat. Genet., 1999, 21, 33-37.

4 S. G. Oliver, Nature, 1996, 379, 597-600.

5 L. Zhang, W. Zhou, V. E. Velculescu, S. E. Kern, R. H. Hruban, S. R. Hamilton, B. Vogelstein and K. W. Kinzler, Science, 1997, 276, 1268-1272.

6 M. R. Martzen, S. M. McCraith, S. L. Spinelli, F. M. Torres, S. Fields, E. J. Grayhack and E. M. Phizicky, Science, 1999, 286, $1153-1155$.

7 T. Ito, K. Tashiro, S. Muta, R. Ozawa, T. Chiba, M. Nishizawa, K. Yamamoto, S. Kuhara and Y. Sakaki, Proc. Natl. Acad. Sci. U. S. A., 2000, 97, 1143-1147.

8 A. Zarrinpar, S. H. Park and W. A. Lim, Nature, 2003, 426, 676-680.

9 S. H. Park, A. Zarrinpar and W. A. Lim, Science, 2003, 299, 1061-1064.

10 S. B. Chen, Q. S. Zhang, X. Wu, P. G. Schultz and S. Ding, J. Am. Chem. Soc., 2004, 126, 410-411.

11 R. P. Hertzberg and A. J. Pope, Curr. Opin. Chem. Biol., 2000, 4, 445-451.

12 A. M. Maffia, I. Kariv and K. R. Oldenburg, J. Biomol. Screening, 1999, 4, 137-142.

13 D. R. Reyes, D. Iossifidis, P. A. Auroux and A. Manz, Anal. Chem., 2002, 74, 2623-2636.

14 D. Figeys and D. Pinto, Anal. Chem., 2000, 72, 330a-335a.
15 S. Takayama, J. C. McDonald, E. Ostuni, M. N. Liang, P. J. A. Kenis, R. F. Ismagilov and G. M. Whitesides, Proc. Natl. Acad. Sci. U. S. A., 1999, 96, 5545-5548.

16 A. Khademhosseini, K. Y. Suh, S. Jon, G. Eng, J. Yeh, G. J. Chen and R. Langer, Anal. Chem., 2004, 76, 3675-3681.

17 A. Folch and M. Toner, Biotechnol. Prog., 1998, 14, 388-392.

18 J. Heo, K. J. Thomas, G. H. Seong and R. M. Crooks, Anal. Chem., 2003, 75, 22-26.

19 A. R. Wheeler, W. R. Throndset, R. J. Whelan, A. M. Leach, R. N. Zare, Y. H. Liao, K. Farrell, I. D. Manger and A. Daridon, Anal. Chem., 2003, 75, 3581-3586.

20 J. Voldman, M. L. Gray, M. Toner and M. A. Schmidt, Anal. Chem., 2002, 74, 3984-3990.

21 A. Ashkin, Proc. Natl. Acad. Sci. U. S. A., 1997, 94, 4853-4860.

22 I. Biran and D. R. Walt, Anal. Chem., 2002, 74, 3046-3054.

23 I. Inoue, Y. Wakamoto, H. Moriguchi, K. Okano and K. Yasuda, Lab Chip, 2001, 1, 50-55.

24 A. Khademhosseini, J. Yeh, S. Jon, G. Eng, K. Y. Suh, J. A. Burdick and R. Langer, Lab Chip, 2004, 4, 425-430.

25 K. Y. Suh, Y. S. Kim and H. H. Lee, Adv. Mater., 2001, 13, 1386-1389.

26 K. Y. Suh, P. Kim and H. H. Lee, Appl. Phys. Lett., 2004, 85, 4019-4021.

27 S. J. Choi, P. J. Yoo, S. J. Baek, T. W. Kim and H. H. Lee, J. Am. Chem. Soc., 2004, 126, 7744-7745.

28 M. Mrksich, C. S. Chen, Y. N. Xia, L. E. Dike, D. E. Ingber and G. M. Whitesides, Proc. Natl. Acad. Sci. U. S. A., 1996, 93, 10775-10778.

29 A. Revzin, R. J. Russell, V. K. Yadavalli, W. G. Koh, C. Deister, D. D. Hile, M. B. Mellott and M. V. Pishko, Langmuir, 2001, 17, $5440-5447$.

30 W. G. Koh, A. Revzin, A. Simonian, T. Reeves and M. Pishko, Biomed. Microdevices, 2003, 5, 11-19.

31 K. Y. Suh and R. Langer, Appl. Phys. Lett., 2003, 83, 1668-1670.

32 A. Folch and M. Toner, Annu. Rev. Biomed. Eng., 2000, 2, 227-256.

33 E. Kim and G. M. Whitesides, J. Phys. Chem. B, 1997, 101, 855-863.

34 Y. J. Sun and G. C. Walker, J. Phys. Chem. B, 2002, 106, 2217-2223.

35 F. Juillerat, H. H. Solak, P. Bowen and H. Hofmann, Nanotechnology, 2005, 16, 1311-1316. 